\title{
From the Editors
}

"Rejuvenating Research Ethics" is the title of our issue this quarter. Why "rejuvenating"? Is that not an odd use of a word? Not really. Research ethics was informed by the Nuremberg Code and the later Geneva Accords. Yet problems continue to arise as possibilities emerge and new populations are considered for research. Janus-like as we move toward the 21st century, we need to look both backward and forward. Some accepted guidelines may require rethinking, just as the challenges of a new age also deserve developing new boundaries.

We begin with an examinations of the conceptual confusion surrounding the notion of "misconduct" in experimental research, and the need to form consensus on norms of conduct even amid diverse cultural influences. Following are four papers that concern the nature of human subjects in research. The next three deal with drug trials. And our interview in this issue examines the effectiveness of the tobacco industry's political activity and the House of Representative's unprecedented move to direct the National Institutes of Health to halt funding for an ongoing grant.

Perhaps the most difficult challenges are those research methods that may cause direct harm to patients who enroll in the study. What about the validity today of double-blind placebo controlled studies when the researchers have every reason to believe that the therapeutic arm may substantially help subjects? Are those enrolled in the placebo arm harmed by the structure itself?
A second moral challenge arises regarding vulnerable populations like children, Alzheimer's disease patients, and the mentally ill. Even if consent is obtained by persons who are legally competent, can research be done that may negatively affect such persons and their care givers and loved ones? Even though consent is given, are the harms truly understood in all their impact on the subject's life? Could others, care givers perhaps, consent on behalf of incompetent patients if the research would benefit a class of such patients?

Still another realm of research ethics has to do with a growing bureaucracy in research ethics. The encrustation of rules leads to a tendency to see the institutional review board (IRB) as a blockade to research, rather than as a committee of peers enthusiastically committed to protecting human beings from harm. Sometimes it is difficult for an IRB to have its rulings about individual research projects enforced. At other times researchers themselves betray an ignorance about the rules and the principles on which ethical research is founded. Is there perhaps too cozy a relation between researchers, drug companies, and the national institutes designed to protect persons?

It is time, then, to return to the roots of research ethics and to renew a social commitment to protecting the most vulnerable persons from research harm. At the very least rejuvenating research ethics requires greater attention by professional journals to papers that report on 
research that might have violated the Helsinki Accord on medical research. In the 1975, 1983, and 1989 versions of the Accord, the World Health Organization proposed the following sanction for noncompliance with the Accord: "Reports of experimentation not in accordance with the principles laid down in this Declaration should not be accepted for publication." Certainly, too, as that Accord recognizes the researcher's own responsibilities within each coun- try to acknowledge and protect research subjects, enhanced teaching of medical researchers is necessary to help them understand the purposes of the Accord. Many medical researchers have never heard of the Helsinki Accord, making it difficult to adhere to its principles. Finally, professional medical associations have a responsibility for oversight of their members and their own publications in this respect. 